\title{
Effect of dehydration by sun or by oven on volatiles and aroma compounds of Trachanas
}

\author{
Stefania CArpino ${ }^{1 *}$, Teresa Rapisarda ${ }^{1}$, Giovanni Belvedere ${ }^{1}$, Photis Papademas $^{2}$, \\ Maria Neocleous ${ }^{3}$, Iris ScAdt $^{1}$, Catia Pasta ${ }^{1}$, Giuseppe Licitra ${ }^{1,4}$ \\ ${ }^{1}$ CoRFiLaC, Regione Siciliana, S.P. 25 km 5 Ragusa-Mare, 97100 Ragusa, Italy \\ ${ }^{2}$ Department of Agricultural Sciences, Biotechnology and Food Science, \\ Cyprus University of Technology, 31 Archbishop Kyprianos Str. Limassol Savings \\ Co-operative Bank Building, 3036 Lemesos, Cyprus \\ ${ }^{3}$ Ministry of Agriculture, Natural Resources and Environment, 1411 Nicosia, Cyprus \\ ${ }^{4}$ D.A.C.P.A., Catania University, Via Valdisavoia 5, 95100 Catania, Italy
}

Received 11 December 2009 - Revised 3rd May 2010 - Accepted 4 May 2010

Published online 18 June 2010

\begin{abstract}
Trachanas is one of the most important traditional food products of Cyprus. It is made from fermented sheep or goat's milk or a mixture of both. The fermented milk is heated and crushed wheat is added to produce a porridge mixture. The mixture is then dried and stored in the form of "biscuits". Dehydration is performed either by sun, at a domestic level, or industrially using an oven. The objective of this study was to detect differences in aroma compounds of sun-dried or oven-dried Trachanas samples. Six samples (three sun-dried batches and three oven-dried batches) were prepared to make a porridge mixture according to the Cypriot tradition. Dried Trachanas samples were chemically analysed by the electronic nose SMart Nose system, by gas chromatography-mass spectrometry (GC/MS) and by gas chromatography-mass spectrometryolfactometry $(\mathrm{GC} / \mathrm{MS} / \mathrm{O})$. Triangle tests were also performed by a panel of 30 people from the CoRFiLaC staff in Ragusa, Italy. Principal component analysis applied to SMart Nose results showed a good separation between sun and oven-dried samples: Sun-dried samples showed a higher variability explained by the traditional process, in comparison to the oven-dried samples. GC/MS and GC/MS/O analysis showed higher numbers of compounds for the sun-dried Trachanas samples. In particular, double the number of odour active compounds were detected by GC/MS/O in the sun-dried samples, revealing that the use of the oven in the dehydration process generally resulted in a lower intensity of aroma. Triangle test confirmed instrumental results and clearly indicated detectable differences by consumers between sun- and oven-dried Trachanas.
\end{abstract}

fermented food / cereal / dehydration / dairy food / aroma compound / electronic nose / gas chromatography / olfactometry

摘要 - 阳光和烤炉干燥对 Trachanas 挥发性化合物和芳香化合物的影响。Trachanas 是塞浦
路斯非常重要的传统食品。其主要是由绵羊奶或者山羊奶或者两者的混合物制成的发酵
乳制品。在加热后的发酵乳中加入全麦粒制成麦片混合物。这个混合物干燥成饼干后败存。在
家庭里采用阳光干燥, 而在工厂里则采用烤炉干燥。本文研究了自然阳光干燥和烤炉干燥
对一些 Trachanas 样品中挥发性化合物和芳香物质的影响。按照塞浦路斯传统的加工方法制
备了 6 份麦片混合物 (3 份是阳光燥, 另外 3 份是烤炉干燥)。采用质谱技术电鼻、质
联用 (GC/MS) 和气相色谱-质谱联用结合嗅觉检测法 (GC/MS/O) 分析了干燥样品的化学

*Corresponding author (通讯作者): carpino@corfilac.it 
成分。同时由来自于意大利 Ragusa CoRFiLaC 的 30 名专业感官评定人员进行了三角测 试。质谱技术电子鼻测定结果的主成分分析结果可以有效地区别阳光干燥和烤炉干燥的样 品, 与烤炉干燥相比, 阳光干燥样品显示了较高的可变性, 原因是其采用传统的加工方法。 GC/MS 和 GC/MS/O 的分析结果表明阳光干燥 Trachanas 样品中化合物的数量较多。特别 在对阳光干燥的样品中, GC/MS/O 检测出的活性风味化合物的数量是烤炉干燥样品的 2 倍, 说明烤炉干燥对风味的损失较小。三角测试证明了仪器分析的结果, 这就意味着消费者能 够明确地区分两种方法干燥的 Trachanas。

\section{发䤃食品 / 谷物 / 脱水 / 乳制品 / 芳香化合物 / 质谱技术电子鼻 / 气相色谱 / 嗅觉检测法}

Résumé - Effet de la déshydratation au soleil ou en four sur les volatiles et composés d'arôme de Trachanas. Le « Trachanas » est l'un des plus importants produits alimentaires traditionnels Chypriotes. Il est préparé à partir de lait de brebis et/ou de chèvre fermenté. Le lait fermenté est chauffé et mélangé à des flocons de blé, formant un mélange de type porridge. Le mélange est ensuite séché en forme de " biscuits ». Le séchage est effectué, soit au soleil à l'échelle domestique, soit dans des fours pour les fabrications industrielles. L'objectif de cette étude était de déterminer les différences en composés d'arôme d'échantillons de Trachanas selon leur mode de séchage. Six échantillons (trois séries séchées au soleil et trois séries séchées au four) ont été comparés, le mélange lait-blé étant préparé selon la tradition chypriote. Les échantillons de Trachanas séchés ont été analysés par le système de nez électronique SMart Nose, par chromatographie en phase gazeuse spectrométrie de masse $(\mathrm{CPG} / \mathrm{SM})$ et par $\mathrm{CPG} / \mathrm{SM}$ - olfactométrie $(\mathrm{CPG} / \mathrm{SM} / \mathrm{O})$. Des tests triangulaires ont également été effectués par un jury de 30 membres du personnel du CoRFiLaC, Ragusa, Italie. Les résultats d'analyse en composantes principales des données du SMart Nose montraient une bonne séparation entre les échantillons selon leur mode de séchage : les échantillons séchés au soleil montraient une variabilité plus grande, liée au procédé traditionnel, que les échantillons séchés au four. Les analyses $\mathrm{CPG} / \mathrm{SM}$ et $\mathrm{CPG} / \mathrm{SM} / \mathrm{O}$ faisaient apparaître un plus grand nombre de composés volatils dans les échantillons séchés au soleil. En particulier, deux fois plus de composés odorants étaient détectés par $\mathrm{CPG} / \mathrm{SM} / \mathrm{O}$ dans les échantillons séchés au soleil, ce qui montre que le séchage des Trachanas en four conduisait à moins d'intensité aromatique. Les tests triangulaires confirmaient les résultats des analyses instrumentales et montraient que les échantillons séchés au soleil et les échantillons séchés au four étaient clairement différenciés par les consommateurs.

aliment fermenté / céréale / déshydratation / produit laitier / composé d'arôme / nez électronique / chromatographie gazeuse / olfactométrie

\section{INTRODUCTION}

Trachanas is produced in Cyprus and is one of the most important traditional products of the island. Around 150 tons were produced in 2007 with a market value of $\sim 1.3$ million euro [15]. Trachanas is a fermented food made from crushed wheat and fermented sheep milk (or goat milk or a mixture of the two), which are mixed together and heated to produce porridge. The porridge is then dried and stored in the form of "biscuits" [6]. In some cases, lemon and/or garlic may be added. Trachanas is produced all over Cyprus with some differences from region to region, especially with respect to its shape.
It is mainly produced during the summertime when milk production is abundant and it is sun-dried to prolong its shelf life through dehydration. Trachanas is consumed during the wintertime as a soup after reconstituting the sun-dried "biscuits" with water. Actually, the name "Trachanas" refers to both the sun-dried "biscuits" and the soup that is made from them.

The chemical composition and the nutritional value of Trachanas mainly depend on the milk and the wheat added during the production process, as well as the proportion of these two ingredients in the recipe. Usually, the milk:wheat proportion is about $2: 1$. Products similar to Cypriot Trachanas are known 
as "Tarhana" in Turkey, "Kishk" in Egypt, Syria and Jordan, "Kushuk" in Iraq and "Tahonya/Talkuna" in Hungary and Finland $[8,11]$.

Trachanas is not hygroscopic and can be stored for long periods without any signs of deterioration. Sun-drying is the traditional method of drying Trachanas and has been used as the drying method for this product for centuries. In the last few years, however, some companies use air-flow ovens, especially when the product is to be sold via the retail chains. The main reason for ovendrying Trachanas relates to food safety, since the product is prevented from coming into contact with airborne contaminants such as insects, dust, and/or other foreign objects. Furthermore, with oven-drying, the procedure is accelerated and becomes more controllable and consistent since the drying does not depend on weather conditions. Of course, the producers who do not sell their products through the supermarket chains but directly to the consumers are still allowed to use sun-drying. A lot of small producers place special nets around or over the product to prevent contact with foreign objects.

Nevertheless, traditional producers believe that the method of drying (in the sun vs. in an oven) has a significant effect on the organoleptic characteristics of the final product. The drying rate of the product under the sun is lower compared to the drying rate using ovens. In the summer, temperatures might reach values up to $40{ }^{\circ} \mathrm{C}$ or even higher, which resembles oven conditions. However, there is a wide diurnal temperature range. During the nights, temperatures might drop down to $20^{\circ} \mathrm{C}$ and lower. The difference in the drying procedure, the temperature as well as sunlight exposure is very likely to affect the characteristics of the final product and this issue is worth looking into. The objective of this study was to assess whether drying methods (sun vs. oven) of Trachanas influence its aroma profile.

\section{MATERIALS AND METHODS}

\subsection{Trachanas production}

Experimental Trachanas was produced in July in the province of Pafos, Cyprus at the village of Statos-Agios Fotios. The Trachanas production required three steps: milk fermentation, porridge production, and porridge drying. Three batches of Trachanas porridge were produced with a 2-day interval in between. Half of the Trachanas porridge from each batch was sun-dried and half was oven-dried.

\subsubsection{Milk fermentation}

Approximately $500 \mathrm{~mL}$ of raw goat milk were placed and stored in an earthenware jar to inoculate the milk naturally from the jar biofilm. Fermentation and souring gradually took place during the following 15 days. On each of these days, $500 \mathrm{~mL}$ of fresh goat milk were added to produce the "mother culture". Experimental Trachanas was produced by adding $1 \mathrm{~L}$ of the mother culture to $100 \mathrm{~L}$ of whole raw goat's milk. This mixture was then stored during the following 3 days and fermented to reach the final pH 5.0.

\subsubsection{Porridge production}

After the fermentation stage, the sour, viscous milk was heated for $5 \mathrm{~min}$ to reach $80{ }^{\circ} \mathrm{C}$ and stirred continuously. Crushed wheat was added at a 2:1 milk:wheat ratio and some salt was added to improve the taste. Heating and stirring continued for $\sim 10$ min until the milk was absorbed by the wheat and the porridge was thick. The mixture was covered and left to cool down during the following $24 \mathrm{~h}$, at room temperature. "Biscuit-like" pieces $(11 \mathrm{~cm} \times$ $6 \mathrm{~cm} \times 2 \mathrm{~cm}$ ) were manually cut with a special scoop. 


\subsubsection{Drying procedure}

Oven-drying. Trachanas pieces were placed on stainless steel perforated trays and stacked on trolleys. Trachanas was dried in an air-flow drying oven (size: $20 \mathrm{~m}^{3}$ ) for 2 days at $40{ }^{\circ} \mathrm{C}$. Perforation of the trays allowed an uniform air flow and drying.

Sun-drying. Trachanas pieces were dried outside, on gridded plastic mats which were placed on a special drying table $(8 \mathrm{~m} \times$ $3 \mathrm{~m} \times 1 \mathrm{~m}$ ) with a gridded top surface. The grids facilitated the air flow and draining of the Trachanas porridge. The table was covered with a very fine net to protect Trachanas pieces from dirt. The drying process lasted 5 days.

Both, sun- and oven-dried Trachanas samples had $\mathrm{pH}$ and water activity ranges of $4.8-5.0$ and $0.48-0.51$, respectively.

\subsection{Trachanas soup preparation and sampling}

Six batches of Trachanas samples produced with goat milk (three sun-dried and three oven-dried) were prepared to make a soup using the following method: $100 \mathrm{~g}$ for each Trachanas sample soaked in $600 \mathrm{~mL}$ of water at room temperature $\left(20^{\circ} \mathrm{C}\right)$ for $90 \mathrm{~min}$. After this time the casserole was put on low-medium heat for $30 \mathrm{~min}$ with constant stirring reaching $90{ }^{\circ} \mathrm{C}$. Four grams of each Trachanas sample were collected for the following analysis.

\subsection{Chemical analysis}

\subsubsection{SMart Nose}

The analysis was performed using an electronic nose, SMart Nose system (from LDZ, Marin-Epagnier, Switzerland), which allows the direct analysis by mass spectrometry (MS) of volatile organic components (VOCs) from liquid and solid samples without separation of the headspace components. The SMart Nose system incorporates the Combi Pal autosampler CTC Analytics AG (CTC Combi Pal with the Cycle Composer software), a high-sensitivity quadrupole mass spectrometer (Inficon AG) with an ionic mass detection ranging from 1 to 200 amu and a user-friendly multivariate analysis software (SMart Nose 1.51) for data acquisition. VOCs of each batch and treatment were subsampled five times and each subsample was analysed in triplicate. Four grams of Trachanas soup were weighted and put into $20-\mathrm{mL}$ vials (adapted for the Combi Pal autosampler) closed with a butyl/PTFE septum and a cap. The samples were randomly placed in the autosampler trays to avoid biases due to external factors. The main operating conditions were as follows: incubation temperature at $60{ }^{\circ} \mathrm{C}$; incubation time of $30 \mathrm{~min}$; injection volume of $2.5 \mathrm{~mL}$; syringe temperature at $100{ }^{\circ} \mathrm{C}$; injector temperature at $160{ }^{\circ} \mathrm{C}$; nitrogen as purge gas, with a purge flow of $200 \mathrm{~mL} \cdot \mathrm{min}^{-1}$; EI ionization mode at $70 \mathrm{eV}$; mass spectrometer scan speed of $0.5 \mathrm{~s} \cdot \mathrm{mass}^{-1}$; mass range of 10-160 amu; and SEM voltage at 1350 . The total acquisition time was set to $170 \mathrm{~s}$ so that three cycles were measured for each injection. The mean value of the three cycles was calculated, and the processed data set was normalized using the atomic ion of $\operatorname{argon}(\mathrm{m} / z=40)$ from air. This mass to charge ratio is subject to practically no contamination from other compounds and the concentration of this gas in the headspace can be considered as constant. Such a normalization makes it possible to correct the drift both within a single series of measurements and between different series.

\subsubsection{Extraction of VOCs and detection by gas chromatography-mass spectrometry (GC/MS)}

Out of the three produced batches, we selected, for each treatment, the one sample 


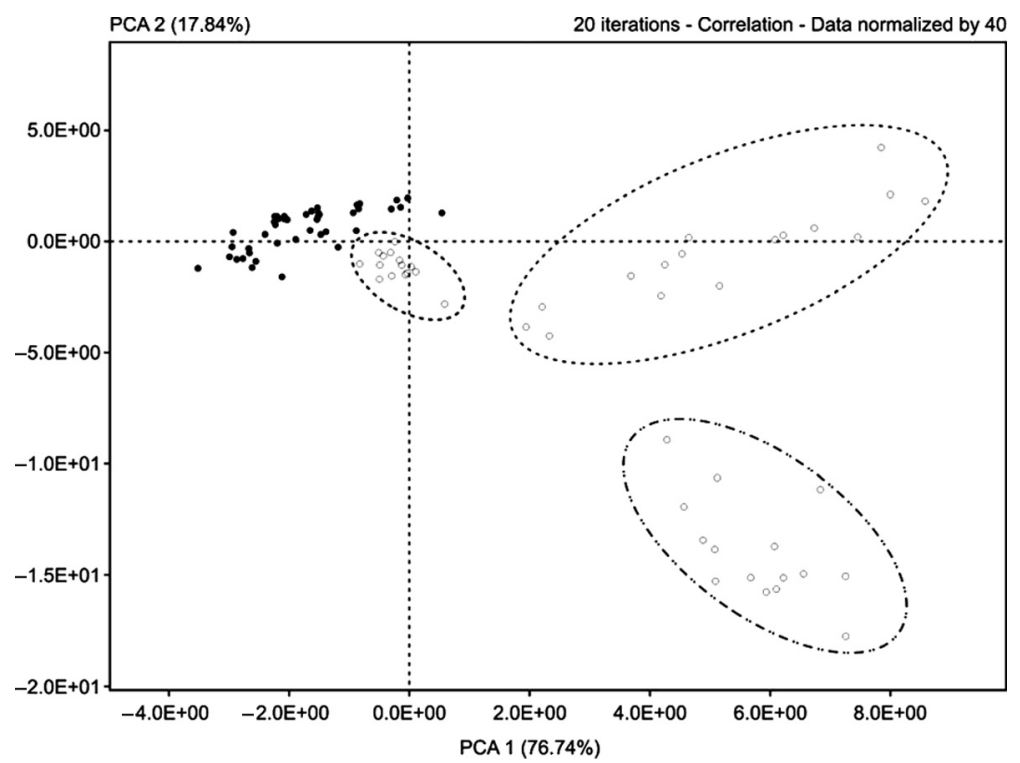

Figure 1. PCA for Trachanas samples ( $\circ$ sun-dried samples; • oven-dried samples) - score plot. Sun-dried samples, batch 1, chosen for further analysis with GC/MS, GC/MS/O and sensory analysis. S. Sun-dried samples, batch 2. ?.) Sun-dried samples, batch 3.

which appeared most homogeneous from preceding SMart Nose PCA (Fig. 1). VOCs were extracted twice by static headspace solid-phase microextraction (SPME) fibre with a 50/30 $\mu \mathrm{m}$ DVB/CAR/PDMS coating (Supelco, Bellefonte, PA, USA). Four grams of Trachanas samples were put into a $22-\mathrm{mL}$ vial and conditioned in a water bath at $70{ }^{\circ} \mathrm{C}$ for $30 \mathrm{~min}$. Further $1 \mathrm{~h}$ of fibre exposition time was required for the static headspace extraction. The fibre was preconditioned before initial use by inserting it into the injector port of a gas chromatography/mass instrument for $1 \mathrm{~h}$ at $225^{\circ} \mathrm{C}$, and was reconditioned between extractions at the same temperature for $5 \mathrm{~min}$, followed by $10 \mathrm{~min}$ at room temperature.

An Agilent 7890A Series GC system (NY, USA) coupled with an Agilent 5975C Mass Selective Detector (NY, USA) (triple axis) was used for the analysis and the identification of the volatile compounds. The
HP-5 capillary column $(30 \mathrm{~m} \times 0.25 \mathrm{~mm}$ ID $\times 0.25 \mu \mathrm{m}$ film thickness, Agilent Technologies, USA) was used to separate the volatile components. The chromatographic conditions were as follows: split/splitless injector at $250{ }^{\circ} \mathrm{C}$; oven program conditions: $35^{\circ} \mathrm{C}$ for $3 \mathrm{~min}, 6^{\circ} \mathrm{C} \cdot \mathrm{min}^{-1}$ to $200{ }^{\circ} \mathrm{C}, 30^{\circ} \mathrm{C} \cdot \mathrm{min}^{-1}$ to $240{ }^{\circ} \mathrm{C}$ for $3 \mathrm{~min}$. Helium pressure (carrier gas) was set at $14.93 \mathrm{psi}$ and the gas flow was $1.2 \mathrm{~mL} \cdot \mathrm{min}^{-1}$. The mass selective detector operated in the scan mode, $5.15 \mathrm{scan} \cdot \mathrm{s}^{-1}$, with $70 \mathrm{eV}$ IE. Peak identification was carried out by comparison of mass spectra with the bibliographic data from the NIST 05 (NIST Standard Reference Database 1A) and Wiley 175 library (Wiley \& Sons, Inc., Germany), and with the linear retention indices (LRI) of authentic standards (Sigma-Aldrich) calculated by running a paraffin series (from C5 to C20) under the same working conditions. 


\subsubsection{Detection by gas chromatography-mass spectrometry-olfactometry}

VOCs of each batch and treatment were extracted twice by SPME. The extraction procedure is described in detail under Section 2.3.2.

An HP 6890 Series GC system gas chromatograph olfactometry coupled with an HP 5973 Mass Selective Detector was also used for the analysis and the identification of the active volatile compounds. The same chromatographic column and conditions used for the GC/MS were applied. The volatile odour active compounds' recognition was performed using the single sniff method where the sniffer was trained using a procedure and a group of standard compounds designed for gas chromatographymass spectrometry-olfactometry (GC/MS/O) subject selection [13]. The standards consisted of a group of eight compounds used to evaluate olfactory acuity and to determine whether a sniffer has specific anosmia for certain odours. The sniffer in this study had no specific anosmia for these standards. The eluted compounds were mixed with a stream of humidified air in a method described by Acree and Barnard [1] and the "sniffer" was continuously exposed to this source for $30 \mathrm{~min}$. The time of response to individual odours perceived by the sniffer was recorded by Charmware software (v 1.12, Datu, Inc., Geneva, NY, USA). These times were converted into retention indices (RIs) for each VOC and displayed by the software as a series of peaks in an aromagram. Retention indices values were calculated relative to a series of normal alkanes $\left(\mathrm{C}_{7}-\mathrm{C}_{18}\right)$ previously injected into the port of the same GC/MS. Each odour compound detected by $\mathrm{GC} / \mathrm{MS} / \mathrm{O}$ analysis was defined by an RI value and an odour description. VOCs were tentatively identified using the Flavornet internet database [3], which contains RIs describing over 550 VOCs identified using GC/MS/O techniques.
Many VOCs were also identified by comparing the RT values obtained from $\mathrm{GC} / \mathrm{MS}$ with the RI values from GC/MS/O. In a few cases, VOCs were identified by comparing the RI and RT values with those from authentic standard compounds injected into the instruments with the same $\mathrm{GC} / \mathrm{MS} / \mathrm{O}$ and $\mathrm{GC} / \mathrm{MS}$ parameters.

\subsection{Sensory analysis}

Out of the three produced batches, we selected, for each treatment, the one sample which appeared most homogeneous from preceding SMart Nose PCA (Fig. 1). Thirty people, selected from the staff of CoRFiLaC, a dairy research centre in Ragusa, Italy, performed a triangle test to determine if the dehydration by sun or by oven had an effect on sensory properties of Trachanas samples.

\subsection{Statistical analysis}

\subsubsection{SMart Nose}

All data sets from SMart Nose results were gathered using the software SMart Nose 1.51. Then a Principal component analysis (PCA) was performed. Though PCA is not a classification method, the program gives the possibility of making a group assignment by Euclidean distances in the multidimensional space created by the PCA. For each separation pattern, a new set of parameters was chosen to calculate the principal components scores.

\subsection{2. $G C / M S$ and $G C / M S / O$}

VOCs presence/absence ratio between sun and oven-dried treatments was analysed with Fisher's exact test [2]. In addition, odour active compounds identified with $\mathrm{GC} / \mathrm{MS} / \mathrm{O}$ were classified into three groups as follows: "Good" $(\mathrm{G})$ represented by floral, green, orange, honey, cake and sweet notes, "Bad" (B) represented by rancid, fried oil, potato and garlic notes, and 
"Not good, not bad" (N) represented by mushroom, nutty and hay notes. Three contingency tables were created one per category $(\mathrm{G}, \mathrm{B}$ and $\mathrm{N})$ by correlating sun/oven treatments and VOCs presence/absence. For each category the significance of the differences between treatments was assessed with Fisher's exact test.

\subsubsection{Sensory analysis}

A triangle test was performed and sensory data were analysed by applying the one-tailed Binomial test $(p=1 / 3 ; q=2 / 3$; and $\alpha=0.05$ ) [16] in order to establish whether the number of people able to recognize the odd sample was higher compared to the number of people who were not able to spot the odd one.

\section{RESULTS AND DISCUSSION}

\subsection{Odour active compounds}

Gas chromatography olfactometry qualitative analysis was performed on sun- and oven-dried Trachanas samples. Presence of compounds was assigned, when detected in all three batches and both replicates. The sun-dried sample showed a richer $(P<0.01)$ odour active compound's profile than the oven-dried sample, with 21 versus 11 VOCs, respectively. There were no differences in frequencies of $\mathrm{N}$ or $\mathrm{B}$ compounds between sun- and oven-dried treatments. Compounds of the $\mathrm{G}$ category were more frequent in the sun-dried compared to the oven-dried treatment $(P<0.01)$. The sundried sample presented all 11 out of 11 VOCs, whereas the oven-dried sample 5 out of 11 .

Both, fermented dairy foods presented the aldehydes as the most representative chemical class in the volatile profile and their origin could depend on the degradation of amino acids and free fatty acids in the sample [17]. Twelve aldehydes, three alcohols, one free fatty esters, one sulphur compound, one terpene and two not identified volatile compounds were found in the sun-dried sample. Nonanal, (E)-2-nonenal, (Z)-2-nonenal and 2,4-decadienal aldehydes are reported in the literature by $\mathrm{Ho}$ and Chen [9] and Hsieh [10] as products of oxidation of unsaturated fatty acid in plants. The terpene compounds likely originate from the degradation of the carotenoid precursors present in the feed [12]. Sulphur compounds could originate from the degradation of methionine aminoacid, as reported by Belitz and Grosch [5], McSweeney and Sousa [14]. The aroma profile of the sundried sample was mainly characterized by mushroom, floral, green, milk, orange, fried oil, potato and sweet notes. Eight aldehydes, two sulphur compounds and one alcohol were found in the oven-dried Trachanas sample, responsible for mushroom, green, orange, fried oil, milk, potato and garlic notes perceptions (Tab. I). In the sun-dried sample, benzenethanol, 2-hexenal, benzaldehyde, 2-octenal, (E,E)-2,4-decadienal, ethyl hexadecanoate, $\gamma$-hexalactone, linalool oxide, cinnamyl alcohol and two not identified compounds were identified as unique compounds, responsible for four pleasant $\mathrm{G}$ flavour notes (floral, milk/honey, cake and sweet), two $\mathrm{N}$ odours (mushroom and nutty) and two B notes (rancid and fried oil). Methyl thiazoline, a sulphur compound, characterized by unpleasant garlic notes, was found as a unique compound in the oven-dried sample. In accordance with the present study, Gocmen et al. [7] also attribute variation in aroma active compounds to different drying procedures. The latter study compared the effect of sundrying versus vacuum-drying on the aroma composition of the Turkish Tarhana.

\subsection{SMart Nose}

The PCA applied to SMart Nose results showed in general a good separation (PC1 76.74\% and PC2 17.84\%) 
Table I. Volatile odour active compounds in Trachanas by SPME and GC/MS/O detection.

\begin{tabular}{|c|c|c|c|c|c|c|c|}
\hline Compounds & Chemical class & Type & Descriptor & $\mathrm{LRI}^{\mathrm{a}}$ & Ident $^{\mathrm{b}}$ & $\operatorname{Sun}^{\mathrm{c}}$ & Oven $^{c}$ \\
\hline NI & - & $\mathrm{N}$ & Mushroom & 1033 & - & $\mathrm{x}$ & \\
\hline NI & - & B & Rancid & 1145 & - & $\mathrm{x}$ & \\
\hline 1-Octen-3-ol ${ }^{*}$ & Alcohol & $\mathrm{N}$ & Mushroom up & 940 & MS, PI & $\mathrm{x}$ & $\mathrm{x}$ \\
\hline Benzenethanol* $^{*}$ & Alcohol & G & Floral & 1070 & MS & $\mathrm{x}$ & \\
\hline Cinnamyl alcohol & Alcohol & G & Oil, floral & 1313 & PI & $\mathrm{x}$ & \\
\hline Hexanal $^{*}$ & Aldehyde & G & Green up & 761 & MS, PI & $\mathrm{x}$ & $\mathrm{x}$ \\
\hline 2-Hexenal & Aldehyde & B & Rancid & 860 & PI & $\mathrm{x}$ & \\
\hline Octanal $^{*}$ & Aldehyde & G & Orange up & 960 & MS, PI & $\mathrm{x}$ & $\mathrm{x}$ \\
\hline Benzaldehyde* & Aldehyde & G & Milk, honey & 965 & MS, PI & $\mathrm{x}$ & \\
\hline (E)-2-octenal* & Aldehyde & B & Fried oil & 1013 & MS & $\mathrm{x}$ & $\mathrm{x}$ \\
\hline Nonanal & Aldehyde & G & Milk, burnt & 1050 & MS, PI & $\mathrm{x}$ & $\mathrm{x}$ \\
\hline 2-Octenal & Aldehyde & $\mathrm{N}$ & Nutty & 1066 & MS, PI & $\mathrm{x}$ & \\
\hline 2,4-Octadienal & Aldehyde & G & Green & 1100 & PI & $\mathrm{x}$ & $\mathrm{x}$ \\
\hline (E)-2-nonenal* & Aldehyde & G & Green up & 1105 & MS, PI & $\mathrm{x}$ & $\mathrm{x}$ \\
\hline (Z)-2-nonenal & Aldehyde & $\mathrm{N}$ & Hay up & 1112 & PI & $\mathrm{x}$ & $\mathrm{x}$ \\
\hline (E,E)-2,4-nonadienal ${ }^{*}$ & Aldehyde & B & Fried oil & 1170 & MS, PI & $\mathrm{x}$ & $\mathrm{x}$ \\
\hline$(\mathrm{E}, \mathrm{E})-2,4$-decadienal ${ }^{*}$ & Aldehyde & B & Fried oil & 1270 & MS & $\mathrm{x}$ & \\
\hline Ethyl hexadecanoate & Ester & G & Cake & 1342 & MS & $\mathrm{x}$ & \\
\hline g-hexalactone & Lactone & G & Sweet & 1318 & PI & $\mathrm{x}$ & \\
\hline Methional & Sulphur & B & Potato & 867 & PI & $\mathrm{x}$ & $\mathrm{x}$ \\
\hline Methyl thiazoline & Sulphur & B & Garlic & 928 & PI & & $\mathrm{x}$ \\
\hline Linalool oxide & Terpene & G & Floral & 1212 & PI & $\mathrm{x}$ & \\
\hline Number of total compounds & & & & & & 21 & 11 \\
\hline
\end{tabular}

${ }^{a}$ LRI, linear retention index; HP-5 capillary column.

${ }^{\mathrm{b}}$ Identification, MS (Wiley library); PI (Internet Data Base: Flavornet).

${ }^{\mathrm{c}}$ Presence of compounds was assigned, when detected in both replicates.

* Identification confirmed by Agilent 7890A GC/ 5975C MS; HP-5 capillary column.

NI, not identified; G, good notes; B, bad notes; N, not good, not bad notes.

According to Fisher's exact test, the sun-dried Trachanas sample contained more $\mathrm{G}$ compounds compared to oven-dried $(P<0.01)$.

between sun- and oven-dried samples. However, there were also differences among the sun-dried samples. Sun-dried samples showed a higher variability explained by the traditional process, than the oven-dried sample group (Fig. 1). Especially sun-dried Trachanas batches 2 and 3 were very heterogeneous in composition. The soup consistence from these batches also appeared granulated and not homogeneous during preparation. Batches 2 and 3 differed most from the oven-dried samples. Figure 2 shows ion fragments of volatile compounds in the loading plot of the PCA. It seems that above-mentioned differences might be explained by a higher $\mathrm{CO}_{2}$ concentration, especially in sun-dried Trachanas batch 3 . We decided to focus on batch 1 samples for any further analysis in order to avoid differences in volatile compounds due to heterogeneity of the product and sampling. Using the reduced data set of only batch 1 samples, PCA still illustrates (Fig. 3) differences in volatiles' composition between oven- versus 


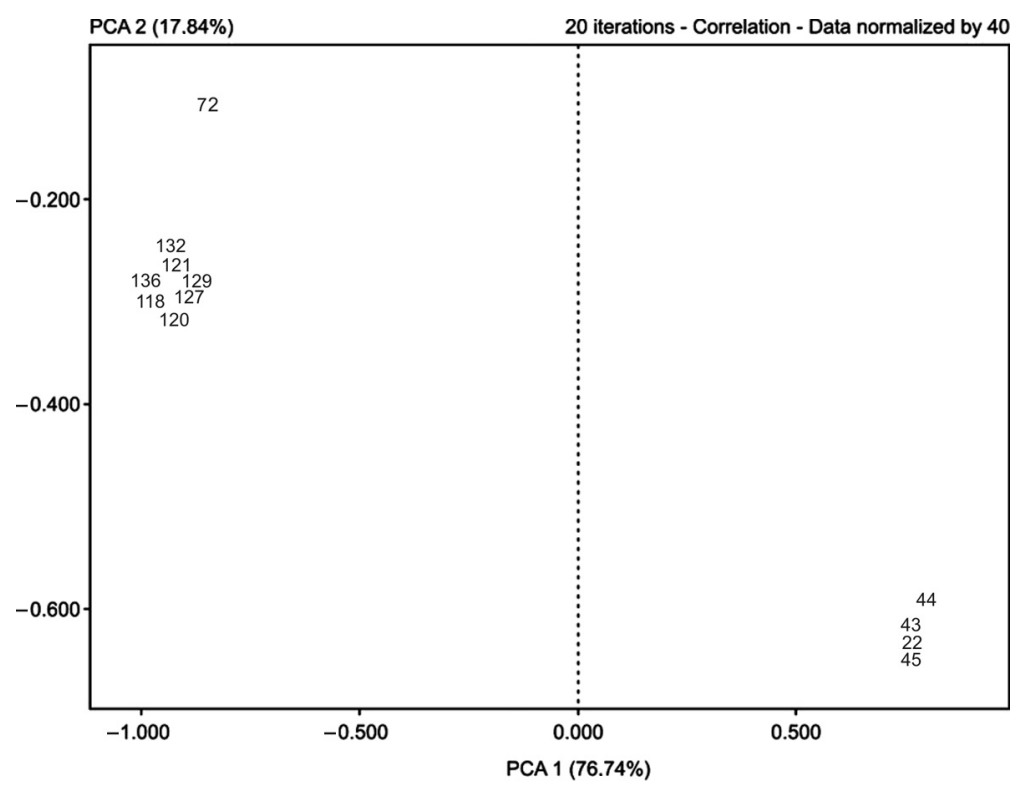

Figure 2. PCA analysis for Trachanas samples: ion fragments of volatile compounds - loading plot. Fragment ions $43-45$ correspond to $\mathrm{CO}_{2}$.

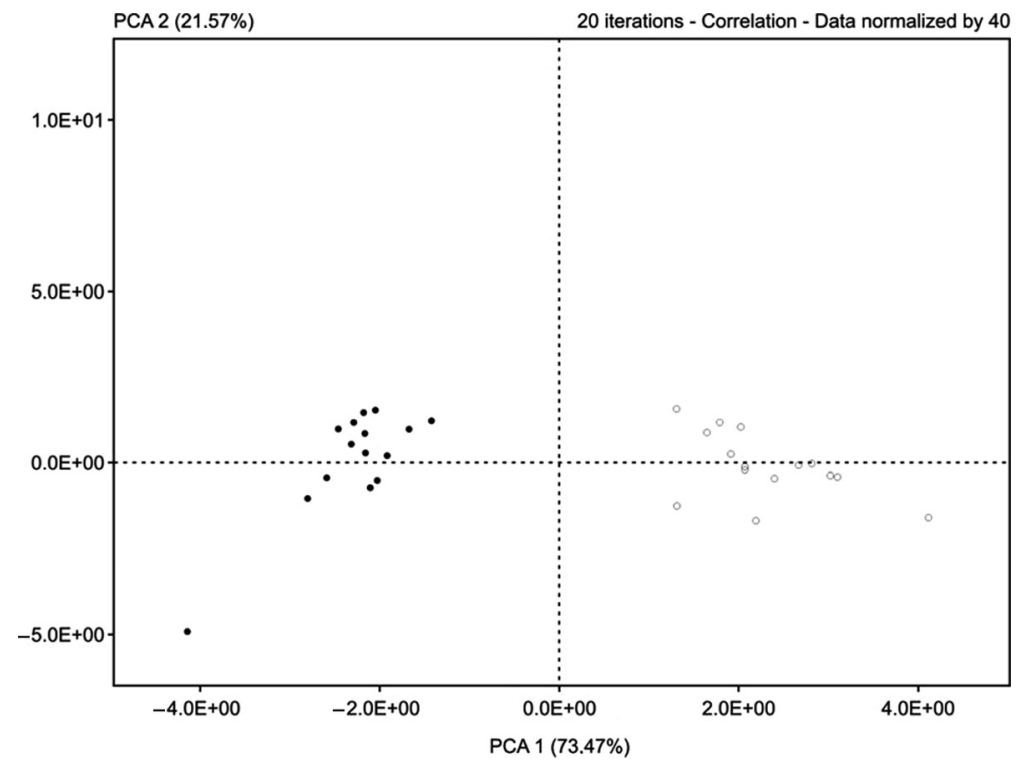

Figure 3. PCA for Trachanas batch 1 samples ( $\circ$ sun-dried samples; • oven-dried samples) - score plot. 
Table II. Volatile compounds in Trachanas sample by SPME and GC/MS detection.

\begin{tabular}{|c|c|c|c|c|}
\hline Compounds & Chemical class & $\mathrm{RT}^{\mathrm{a}, \mathrm{b}}$ & Sun & $\overline{\text { Oven }}$ \\
\hline Hexanoic acid & Acid & 13.1 & $\mathrm{x}$ & $\mathrm{x}$ \\
\hline Octanoic acid & Acid & 18.0 & $\mathrm{x}$ & $\mathrm{x}$ \\
\hline n-Decanoic acid & Acid & 22.3 & $\mathrm{x}$ & $\mathrm{x}$ \\
\hline Heptanoic acid & Acid & 15.1 & $\mathrm{x}$ & \\
\hline Nonanoic acid & Acid & 19.7 & $\mathrm{x}$ & \\
\hline Undecanoic acid & Acid & 25.8 & $\mathrm{x}$ & \\
\hline Tetradecanoic acid & Acid & 29.5 & $\mathrm{x}$ & \\
\hline n-Hexadecanoic acid & Acid & 32.1 & $\mathrm{x}$ & \\
\hline Heptanol & Alcohol & 12.2 & $\mathrm{x}$ & \\
\hline 1-Octen-3-ol & Alcohol & 12.5 & $\mathrm{x}$ & $\mathrm{x}$ \\
\hline (Z)-2-octen-1-ol & Alcohol & 14.8 & $\mathrm{x}$ & \\
\hline 1-octanol & Alcohol & 14.9 & $\mathrm{x}$ & $\mathrm{x}$ \\
\hline Phenylethyl alcohol & Alcohol & 16.1 & $\mathrm{x}$ & $\mathrm{x}$ \\
\hline Nonanol & Alcohol & 17.4 & $\mathrm{x}$ & \\
\hline 2-Hexyl-1-decanol & Alcohol & 22.8 & & $\mathrm{x}$ \\
\hline 2-Methyl-1-penten-3-ol & Alcohol & 25.6 & $\mathrm{x}$ & \\
\hline Hexanal & Aldehyde & 7.5 & $\mathrm{x}$ & $\mathrm{x}$ \\
\hline 2-Hexanal & Aldehyde & 9.0 & & $\mathrm{x}$ \\
\hline Heptanal & Aldehyde & 10.3 & $\mathrm{x}$ & $\mathrm{x}$ \\
\hline 2-Heptanal & Aldehyde & 11.9 & & $\mathrm{x}$ \\
\hline Benzaldehyde & Aldehyde & 12.0 & $\mathrm{x}$ & \\
\hline Octanal & Aldehyde & 13.1 & $\mathrm{x}$ & \\
\hline (E,E)-2,4-heptadienal & Aldehyde & 13.3 & $\mathrm{x}$ & $\mathrm{x}$ \\
\hline Benzene acetaldehyde & Aldehyde & 14.2 & $\mathrm{x}$ & $\mathrm{x}$ \\
\hline 2-Octenal & Aldehyde & 14.6 & $\mathrm{x}$ & $\mathrm{x}$ \\
\hline Nonanal & Aldehyde & 15.8 & $\mathrm{x}$ & $\mathrm{x}$ \\
\hline (E)-2-nonenal & Aldehyde & 17.2 & $\mathrm{x}$ & $\mathrm{x}$ \\
\hline 4-Ethyl-benzaldehyde & Aldehyde & 17.3 & $\mathrm{x}$ & \\
\hline Decanal & Aldehyde & 18.3 & $\mathrm{x}$ & $\mathrm{x}$ \\
\hline (E,E)-2,4-nonadienal & Aldehyde & 18.5 & $\mathrm{x}$ & $\mathrm{x}$ \\
\hline (E,E)-2,4-decadienal & Aldehyde & 20.8 & $\mathrm{x}$ & $\mathrm{x}$ \\
\hline Tetradecanal & Aldehyde & 26.8 & $\mathrm{x}$ & \\
\hline Octanoic acid, ethyl ester & Ester & 18.1 & $\mathrm{x}$ & $\mathrm{x}$ \\
\hline Acetic acid, 2-phenylethyl ester & Ester & 19.5 & $\mathrm{x}$ & \\
\hline Decanoic acid, ethyl ester & Ester & 22.5 & $\mathrm{x}$ & $\mathrm{x}$ \\
\hline Dodecanoic acid, ethyl ester & Ester & 26.5 & $\mathrm{x}$ & \\
\hline Tetradecanoic acid, ethyl ester & Ester & 30.1 & $\mathrm{x}$ & \\
\hline 2-Heptanone & Ketone & 10.0 & & $\mathrm{x}$ \\
\hline 3-Octen-2-one & Ketone & 14.1 & $\mathrm{x}$ & $\mathrm{x}$ \\
\hline 2-Nonanone & Ketone & 15.5 & $\mathrm{x}$ & \\
\hline 3-Nonen-2-one & Ketone & 16.7 & $\mathrm{x}$ & \\
\hline 2-Decanone & Ketone & 18.0 & $\mathrm{x}$ & \\
\hline Number of total compounds & & & 38 & 23 \\
\hline
\end{tabular}

${ }^{\mathrm{a}} \mathrm{RT}$, retention time; HP-5 capillary column.

${ }^{\mathrm{b}}$ Identification, MS (NIST/Wiley library).

According to Fisher's exact test, the sun-dried Trachanas sample contained more volatiles compared to oven-dried $(P<0.01)$. 


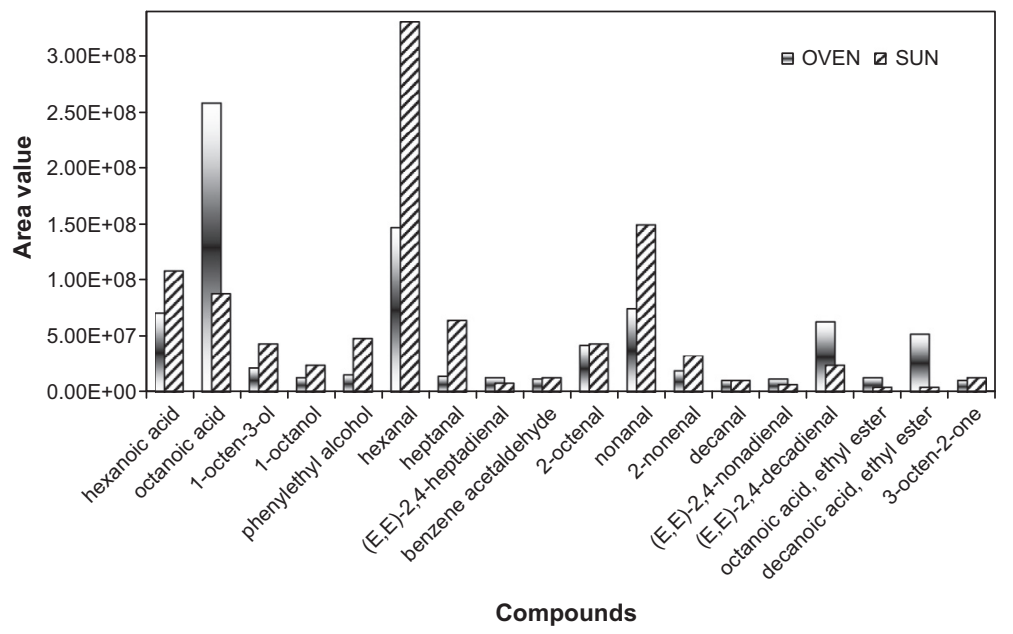

Figure 4. Area values of common VOCs in sun-dried and oven-dried Trachanas sample 1 extracted by SPME and detected with GC/MS. Area value: the average of two replicates was considered.

sun-dried Trachanas samples (PC1 73.47\% and PC2 21.57\%).

\subsection{Volatile compounds}

Gas chromatography-mass spectrometry analysis was performed on sun- and ovendried Trachanas samples. Presence of compounds was assigned, when detected in both replicates of batch 1 . The sun-dried sample showed a higher $(P<0.01)$ number of VOCs than the oven-dried sample (38 vs. 23 VOCs). The volatile profile of sun-dried Trachanas sample was characterized by 14 aldehydes, 8 free fatty acids, 7 alcohols, 5 free fatty esters and 4 ketones, whereas the volatile profile of the oven-dried Trachanas sample was characterized by 12 aldehydes, 3 free fatty acids, 4 alcohols, 2 free fatty esters and 2 ketones. Table II shows the differences in number and chemical class of volatile compounds between the sun- and oven-dried Trachanas samples: heptanoic acid, nonanoic acid, undecanoic acid, tetradecanoic acid and n-hexadecanoic acid were found as unique free fatty acids in the sun-dried sample. Heptanol,
(Z)-2-octen-1-ol, nonanol and 2-methyl-1penten-3-ol were found as unique alcohol volatile compounds in the sun-dried sample, whereas, 2-hexyl-1-decanol was found as unique volatile compound in the oven-dried sample.

In the aldehyde chemical class, benzaldehyde, octanal, 4-ethyl-benzaldehyde and tetradecanal were found as unique aldehyde volatile compounds in the sun-dried sample, whereas, 2-hexanal and 2-heptanal were detected as unique compounds in the ovendried sample. In free fatty ester chemical class, acetic acid-2-phenylethyl ester, dodecanoic acid ethyl ester and tetradecanoic acid ethyl ester were found as unique compounds in the sun-dried sample. Moreover, 2-nonanone, 3-nonen-2-one and 2-decanone were detected as unique compounds in sun-dried samples, whereas just 2-heptanone was detected as unique compound in the oven-dried sample.

Several volatile compounds were detected as common in both sun- and ovendried samples; some of these compounds showed big differences in the area value Figure 4 shows area values of volatile 
organic compounds which were common in both treatments. The average of the two replicates was considered. The area values of hexanal, heptanal, nonanal hexanoic acid, phenylethyl alcohol and 1-octen-3-ol are apparently higher in the sun-dried compared to the oven-dried Trachanas sample, whereas the oven-dried Trachanas sample seemed to have a greater area value for octanoic acid, (E,E)-2,4-decadienal and decanoic acid, ethyl ester. Traditional sun dehydration technology promotes the photo-oxidation processes, whereas the industrial one promotes the auto-oxidation processes in these fermented dairy products. These results are in agreement with data reported in the literature [4], especially for hexanal, a photo-oxidation product, (E,E)-2,4-decadienal and (E,E)-2,4heptadienal, auto-oxidation products.

\subsection{Sensory analysis}

The triangle test from sensory analysis showed that the dehydration by sun or by oven had an effect on Trachanas samples with a high statistical meaning. One-tailed Binomial test ( $p=1 / 3$ and $q=2 / 3$ ) in fact showed a $P$-value $<0.001$, indicating that a significant number of people $(67 \%)$ were able to identify the odd product. Thus, the two products were different from each other from a consumer point of view.

\section{CONCLUSIONS}

Trachanas, the most important fermented traditional product of Cyprus, is produced at domestic level by sun dehydration or industrially by oven dehydration. Several chemical analyses were performed to study the influences of dehydration processes on Trachanas aroma quality. The PCA applied to SMart Nose results showed a clear separation (PC1 76.74\% and $\mathrm{PC} 2 \quad 17.84 \%$ ) between sun- and oven-dried samples, indicating a sensible difference in their aroma profiles. Sensorial investigations demonstrated that differences between traditional and industrial Trachanas products are detectable by consumers. Volatile compounds in sun-dried samples seem to be more heterogeneous. Higher variability might be explained by variation in drying temperature and possible effects of other factors such as sunlight irradiation. The traditional sun dehydration technology is likely to favour the production of more pleasant odour active compounds relative to oven-drying. Differences might be explained, at least in part, by the photo-oxidation processes which are promoted by the sun-drying procedure as well as the auto-oxidation processes during industrial production of these fermented dairy products, which are probably due to the high temperature of the oven used in the dehydration step. However, there might be a need for some regulations regarding the sun-drying procedure, in order to moderate heterogeneity of the Trachanas aroma profile. Controlled parameters might include minimum temperature and frequency of rolling over of the Trachanas pieces. In the present study, the samples have not been turned during the drying process. However, the rolling over might be helpful in order to dry out evenly all sides.

\section{REFERENCES}

[1] Acree T.E., Barnard J., Gas chromatography-olfactometry using Charm analysis, in: Maarse H. (Ed.), Trends in flavour research, Proceedings of the 7 th Weurman Flavour Research Symposium, 35, Elsevier, Noordwijkerhout, Amsterdam, Netherlands, 1994, pp. 211-220.

[2] Agresti A., Two-way contingency tables, in: Agresti A. (Ed.), An introduction to categorical data analysis, John Wiley and Sons, Inc, New York, USA, 1996, pp. 39-44.

[3] Arn H., Acree T.E., Flavornet, Worldwide Web resource:http://www.nysaes.cornell.edu/flavornet/ index.html, 1997.

[4] Aruoma O.I., Cuppet S.L., Antioxidant methodology. In vivo and in vitro concepts, 1st edn., AOCS Press, Champaign, Illinois, USA, 1997. 
[5] Belitz H.D., Grosch W., Food chemistry, in: Hadziyev D. (Ed.), Aroma substances, Springer-Verlag, New York, USA, 1986, pp. 257-303.

[6] Blandino A., Al-Aseeri M.E., Pandiella S.S., Cantero D., Webb C., Cereal-based fermented foods and beverages, Food Res. Int. 36 (2003) 527-543.

[7] Gocmen D., Gurbuz O., Rouseff R.L., Smoot J.M., Dagdelen A.F., Gas chromatographic-olfactometric characterization of aroma active compounds in sun-dried and vacuum-dried Tarhana, Eur. Food Res. Technol. 218 (2004) 573-578.

[8] Hayta M., Alpaslan M., Baysar A., Effect of drying methods on functional properties of Tarhana: a wheat flour-yogurt mixture, J. Food Sci. 67 (2002) 740-744.

[9] Ho C.T., Chen Q., Lipids in food flavours: an overview, in: Ho C.T., Hartman T.G. (Eds.), Lipids in food flavours, ACS Symposium Series 558, American Chemical Society, Washington, DC, USA, 1994, pp. 2-14.

[10] Hsieh J.R., Contribution of lipoxygenase pathway to food flavours, in: Ho C.T., Hartman T.G. (Eds.), Lipids in food flavours, ACS Symposium Series 558, American Chemical Society, Washington, DC, USA, 1994, pp. 30-48.
[11] Kose E., Cagindi O.Z., An investigation into the use of different flours in Tarhana, Int. J. Food Sci. Technol. 37 (2002) 219-222.

[12] Lewinsohn E., Sitrit Y., Bar E., Azulay Y., Ibdah M., Meir A., Yosef E., Zamir D., Tadmor Y., Not just colors carotenoids degradation as a link between pigmentation and aroma in tomato and watermelon fruit, Trends Food Sci. Technol. 16 (2005) 407-415.

[13] Marin A.B., Acree T.E., Barnard J., Variation in odor detection thresholds determined by Charm analysis, Chem. Senses. 13 (1988) 435-444.

[14] McSweeney P.H.L., Sousa M.J., Biochemical pathways for the production of flavour compounds in cheeses during ripening: a review, Lait 80 (2000) 293-324.

[15] Ministry of Finance Statistical Service, Republic of Cyprus, Worldwide Web resource: http://www.mof.gov.cy/mof/cystat/ statistics.nsf/index_en/ index_en, 2003-2008.

[16] O’Mahony M., The binomial test: applications in sensory difference and preference testing, in: O’Mahony M. (Ed.), Sensory evaluation of food: statistical methods and procedures, Marcel Dekker Inc, New York, NY, USA, 1986, pp. 57-90.

[17] Smit G., Smit B.A., Engels W.J.M., Flavour formation by lactic acid bacteria and biochemical flavour profiling of cheese products, FEMS Microbiol. Rev. 29 (2005) 591-610. 